\title{
Los espacios urbanos de sociabilización de los Transexuales en la ciudad de Santiago de Chile
}

\author{
The urban spaces of socialization of the Transsexuals in the city of Santiago, Chile
}

\author{
Martin Ignacio Torres Rodriguez \\ Universidade Estadual Paulista, Campus Presidente Prudente \\ martin.torres.r@gmail.com \\ Raul Borges Guimarães \\ Universidade Estadual Paulista, Campus Presidente Prudente \\ archguimaraes@aol.com
}

\section{Resumo}

Este artículo presenta una discusión sobre la transexualidad y la transformación del cuerpo y cómo esta transformación se integra y repercute dentro de la ciudad, en este caso la capital de Chile, Santiago. Se discute así, cuáles son los espacios urbanos que los transexuales pueden ocupar libremente, teniendo un ingreso sin problemas a los espacios públicos, como también a lugares de esparcimiento íntegros y de calidad. Dando y reconociendo cuales son los espacios habitados por aquellos cuerpos transexuales, como también señalando las limitaciones y problemáticas a las que se enfrenta esta población, se demuestra así que la cuestión del género y los cambios corporales repercuten en el lugar que habitamos, como también esas imposiciones sociales determinan las directrices de los cuerpos.

Palavras - chave: Ciudad; transexualidad; espacios urbanos; sociabilización; Santiago de Chile.

\begin{abstract}
This article presents a discussion of transsexuality and the transformation of the body and how this transformation is integrated and impacts within the city, in this case, the capital of Chile, Santiago. We discuss which are the urban spaces that transsexuals can use freely, having no problems with the entry into public spaces, as well as quality and integral recreational places. Giving and recognizing which are the places inhabited by those transsexual bodies, as well as indicating the limitations and problems that this population faces, we demonstrate that gender and body changes affect the place we inhabit, as well as those social impositions determine the guidelines of the bodies.
\end{abstract}

Keywords: City; transsexuality; urban spaces; sociability; Santiago of Chile. 


\section{Introducción}

La ciudad de Santiago, capital de Chile, presenta una población que ha sido discriminada y excluida de todo espacio habitable y, por ende, también retraída del espacio urbano social y público. Lo público se ve dirigido por los cánones de la 'buena sociedad', de la 'buena familia', la ética, la moral, y el 'buen ciudadano'; todos estos patrones impuestos por el excesivo control social, que impone reglas y costumbres a los países occidentales.

La población estudiada a fondo para este artículo representa una mitificación de no poder entrar dentro de esas normas impuestas; catalogados muchas veces de no cuadrar en estas estrictas normas sociales, se ven discriminados y marginalizados de poder obtener derechos y deberes como cualquier otro ciudadano. Y es que nuestra población analizada rompe con las estructuras impuestas, transgrede los límites psíquicos y corporales, siendo muchas veces estos últimos los más notorios y reprochables por la sociedad.

Hablamos de los transexuales que habitan Santiago: hombres y mujeres transexuales que transitan no sólo por las calles de la ciudad, sino que también transitan de un sexo a otro, transformando sus cuerpos, su vestimenta, sus nombres y el rol impuesto en la sociedad desde el momento de nacer.

Primeramente, es importante hacer la reflexión de qué es ser transexual y las diferencias entre el género y el sexo. Debemos evidenciar también las diferencias lingüísticas, tal como expone Silva cuando explica lo complejo del tema, debido a la gama y las distintas categorías del género:

Assim, há um problema lingüístico a ser evidenciado em relação às associações dos termos travesti, transgênero e transexual para nomear pessoas que possuem uma dissonância entre o corpo biológico e a identidade de gênero. A tradução de travesti para o inglês seria 'transvestites'. Contudo o termo em inglês não se adéqua aos sujeitos aqui enfocados, já que este termo é utilizado para nomear homens que se vestem 'eventualmente' como mulheres. As pessoas aqui enfocadas são melhor definidas, na língua inglesa, pela palavra transgender. No espanhol, qualquer pessoa que realize intervenções em seu corpo são nomeadas de 'transexuales', independente do grau de intervenção, desde o implante do silicone, até a cirurgia de transgenitalização. ${ }^{1}$ (SILVA, 2008, p. 2).
Para este artículo se entiende que el transexual ha nacido con un sexo biológico determinado, pero su género tanto social como psíquico no pertenece a éste, generando así una discordia entre el cuerpo y la mente. Esta discordia lo/la lleva a querer generar un cambio, el cual es sin duda necesario para poder colocar al cuerpo acorde con la psiquis. Es lo que expresa Hammarberg cuando coloca que:

La identidad de género es uno de los aspectos más fundamentales de la vida. Habitualmente, se asigna el sexo de una persona al nacer, convirtiéndose a partir de este momento en un hecho social y legal. Sin embargo, un número relativamente pequeño de individuos tienen problemas con pertenecer al sexo registrado al nacer. Lo mismo puede ocurrir con personas intersexuales cuyos cuerpos y, en ocasiones, su anatomía genital incorporan ambos o ciertos aspectos tanto de la fisiología masculina como femenina. Para otras personas los problemas surgen porque su auto percepción innata no está en conformidad con el sexo que se les asignó al nacer; a estas personas se les hace referencia como personas 'transgénero' o 'transexuales'. (HAMMARBERG, 2010, p. 25).

Esa disconformidad con el sexo asignado al momento de nacer y las imposiciones sociales de rol de género que las personas transexuales no quieren cumplir son justamente lo que lleva a la necesidad de un cambio y, finalmente, llevarlo a cabo es lo que genera el principal impacto en la sociedad, en la ciudad y en los espacios urbanos, ya que estos cambios son visibles e inevitablemente notorios. Sin embargo, a lo largo del proceso de cambio de sexo por el cual tienen que pasar los transexuales se generan un sinnúmero de problemáticas en las diversas etapas del proceso, ya sea discriminación a simple vista en las calles de la urbe o al tener contacto con una persona y/o entidad.

Los transexuales santiaguinos, tanto en su tránsito de un género a otro, como en el tránsito en las calles de Santiago, deben lidiar con que se mueven en un medio urbano hostil, en el cual tratan de expresar libremente su vida, su cuerpo y su género, o, simplemente, de transitar sin ser vistos. Los temores a la discriminación han generado un deseo de invisibilidad en la población transexual, y la búsqueda de espacios de libre expresión es el tema central a analizar en este artículo, dejando en claro que todo ser 
humano necesita sin duda un espacio de libre expresión, como a su vez un lugar de esparcimiento y de sociabilización con sus pares y con personas distintas, alimentando así la cultura y la riqueza propia de la ciudad metropolitana.

Con este propósito se realizó una entrevista a 36 personas transexuales que viven en la ciudad de Santiago, se confeccionaron mapas donde se expresan aquellos lugares mencionados por los entrevistados, y posteriormente también se hizo un levantamiento de suelo de los lugares puesto en escena dentro del articulo, pudiendo así constatar las vivencias dentro de los lugares mencionados. Vale decir también, que para la metodología es inevitable destacar que el mismo autor es transexual y vive en la ciudad de Santiago, siendo así esta una investigación participativa y no solo observadora.

\section{La Geografía, el Género y la Ciudad}

No se puede olvidar la fuerte ligazón entre la geografía y el género. Esta relación es necesaria para ambos lados: el género tiene todo que ver con la geografía, como ésta también tiene una estrecha relación con el tema del género. Es por ello que durante años las literaturas se han dedicado al tema de la geografía del género, siendo importante destacar los aportes anglosajones en estos procesos, imponiendo también nuevas temáticas a la geografía del género.

Se tiene que el género es una construcción social compleja, una instancia de aprendizajes y roles sociales que se deben y que además se desean cumplir, y por otro lado se tiene que el sexo biológico de una persona viene determinado del nacimiento, sea este femenino, masculino o intersexual, por lo que se genera así una de las mayores diferencias entre el género y el sexo. Justamente, es así como explican algunas autoras tales como Ana Sabanté, Juana Rodríguez Moya y María Díaz Muñoz al exponer las diferencias entre el género y el sexo dentro de una sociedad y cómo éstas se manifiestan de maneras diferentes en las distintas sociedades y lugares: "Género: este concepto hace referencia a 'todas las diferencias entre hombres y mujeres que han sido construidos socialmente'; por ello la diferencia con respecto al sexo es nítida, en cuanto que éste es biológico.” (SABANTÉ; RODRÍGUEZ, 1995. p. 14).

El género finalmente es una situación territorial, y es en ese prisma que la geografía trae una importante visión del territorio y de su apropiación, ya sea ésta una apropiación del cuerpo transexual (mediante cambios: hormonas, cirugías, cambio de sexo), como también, y más relevante aún para este artículo, una apropiación de los espacios urbanos, un habitar libremente los lugares de sociabilización, una generación de territorio urbano con propiedad y con identidad.

También explican las autoras Ana Sabanté, Juana Rodríguez Moya y María Díaz Muñoz que el principal objetivo de la geografía del género es analizar las relaciones del espacio y cómo los diferentes lugares pueden traer diferencias con el género. Esto es mejor explicado en la reflexión de las autoras cuando colocan que: "El género como construcción social tiene importantes variaciones territoriales, lo que no ocurre con el sexo". (SABANTÉ; RODRÍGUEZ, 1995, p. 14).

Reflexión de la cual también se deja ver que, como explican más adelante las mismas autoras, las diferentes culturas, tanto occidental como oriental, ven el sexo y el género de forma diferente, siendo sorprenderte el descubrir que en muchos lugares de oriente no existe una represión tan fuerte como en occidente referente a los temas transexuales, siendo éstos vistos de forma normal como un tercer sexo, e incluso catalogados como dioses o castas especiales.

Se genera así el debate de que en occidente la heteronormatividad del sexo y el género ha causado sin duda una expropiación de los terrenos corporales y los espacios urbanos habitables de libre sociabilización en donde se pueda vivir un género, un sexo y una orientación diferente a la heteronormatividad impuesta por la sociedad occidental.

La heteronormatividad queda plasmada en la exigencia de una corporalidad binaria, con tan solo dos posibilidades 'correctas': el ser hombre o ser mujer, limitando la inmensa gama de cuerpos, opciones, géneros y sexualidades que pueden ser llevadas a cabo por las personas. Es así como lo expone Laqueur, cuando expresa que "Al comienzo, lo que llamamos sexo y género estaba explícitamente vinculado en el 'modelo de sexo único' dentro de un círculo de significado desde el que era imposible escapar a un supuesto sustrato biológico". (LAQUEUR, 1994, p. 27-8).

Esta heteronormatividad no sólo rige los cánones de la orientación sexual, sino que también dirige un patrón normativo de sexo y género visto como una sola cosa, siendo que estos pueden ser (son) dispares, en especial en la población transexual.

En este sentido es cuando Espinosa expresa la rigidez de la heteronormatividad: lo que se nos está permitido ser dentro de los límites binarios (hombremujer). Se manifiesta que estos patrones han sido socialmente delimitados por cánones estrictos de la heterosexualidad normativa y patriarcal, que por lo general está dirigida por conceptos machistas que marginan a cualquiera que se salga un poco del patrón 
denominado como 'común'. Dentro de estos conceptos no caben ideas de parejas diferentes como tampoco de cuerpos distintos. Estas 'otras' formas de vivir y de expresarse chocan e interrumpen a la sociedad, generando la discordia entre nuestro sentir interno y lo que socialmente se nos exige ser, colocando así a la transexualidad en un plano complejo, ya que como el mismo autor explica: "Por un lado, el tema del transexualismo se ubica en un escenario donde se debate qué se es y, complicando las cosas, qué está permitido ser como seres humanos". (ESPINOSA, 2008, p. 20).

La heterosexualidad impuesta sería una forma de coartar las múltiples formas de coexistir en el espacio urbano, y la transexualidad sería una forma de transgredir las normas heteronormativas llevando al cuerpo a una exposición dentro de la ciudad, transgrediendo las normas visibles de la sociedad, imponiendo en el espacio una ruptura de lo establecido de forma heteronormativa y haciendo así un uso del espacio urbano, como explica Doreen Massey en el siguiente párrafo, de una manera diversa, heterogénea y con múltiples dimensiones:

Primeiro, reconhecemos o espaço como o produto de inter-relações, como sendo constituído através de interações, desde a imensidão do global até o intimamente pequeno. [...] Segundo, compreendemos o espaço como a esfera da possibilidade da existência da multiplicidade, no sentido da pluralidade contemporânea, como a esfera na qual distintas trajetórias coexistem; como a esfera, portanto, da coexistência da heterogeneidade. Sem espaço, não há multiplicidade; sem multiplicidade, não há espaço. Se espaço é, sem dúvida, o produto de inter-relações, estão deve estar baseado na existência da pluralidade. Multiplicidade e espaço são co-constitutivos. Terceiro, reconhecemos o espaço como estando sempre em construção². (MASSEY, 2005, p. 29)

Dentro de esto, el espacio urbano santiaguino vinculado a la sociabilización de la población, y aquellos espacios de esparcimiento, exige tener lugares destinados a una diversidad sexual, diversidad corporal y de opciones humanas que han sido retraídas por la heteronormatividad que se expresa no sólo en lo cuerpos, sino que también en los espacios urbanos. Se destinan así pequeños reductos con otras alternativas fuera de las normas binarias Hombre-Mujer (MachoHembra $)^{3}$, con otras alternativas al sexo heterosexual y con otras gamas corporales, y es así como estos pequeños reductos se sumergen y se concentran en la invisibilidad del centro urbano, dando así una connotación de diversidad sexual a aquellos barrios.

Entonces aquellos espacios urbanos de sociabilización $\mathrm{LGBTTI}^{4}$ quedan reducidos a la invisibilidad del espacio ciudadano, confinados a estrechos horarios, y hechos para ser vistos sólo a la sombra, dejando también a las personas en la penumbra.

Y la pregunta es, si realmente aquellos espacios son lugares urbanos en donde el transexual finalmente tiene cabida o son otra instancia de reproducir una sociedad normativa, vale decir una discriminación dentro de un mismo grupo discriminado.

\section{Santiago y los Espacios Urbanos de Esparcimiento}

Se debe comenzar con una descripción básica para localizarse en el área de estudios, sobre la ubicación y algunas determinantes de la ciudad de Santiago capital de Chile, ubicada en la XIII región del país, llamada Región Metropolitana 5 .

Santiago se ubica con las coordenadas $33^{\circ} 26^{\prime} 16^{\prime \prime}$ Sur y $70^{\circ} 39^{\prime} 01^{\prime \prime}$ Oeste, lo cual le da una condición climática con cuatro estaciones marcadas, lo que se denomina clima mediterráneo continental. ${ }^{6}$

A continuación, se presenta un mapa básico de Chile y las comunas de la ciudad de Santiago, representando en color rojo el centro de Santiago, comuna que será las más importantes a tratar para este articulo. (Ver mapa $\mathrm{N}^{\mathrm{o}} 1$ ).

La urbanización y creciente diversidad en general que presenta la ciudad de Santiago no suele verse en una diversificación de los espacios utilizables para las diferentes opciones sexuales y para libre expresión de los cuerpos, en este caso, los transexuales. Sin embargo, la masiva concentración de los espacios urbanos dirigidos a una diversidad sexual están concentrados de tal forma que finalmente son excluyentes, como también es marcada la connotación gay $\mathrm{y}$, en algunos casos, lésbica, situación que deja fuera e incluso marginalizados a los transexuales.

Esta masiva concentración también genera que en estos lugares exista una mayor mezcla de culturas. Sin embargo, dentro de los análisis hechos después de las conversaciones, entrevistas y visitas a los lugares, se puede constatar que estos espacios de esparcimiento si bien son catalogados como de diversidad y libre expresión LGBTT, en la práctica no son tal, ya que las entradas en muchos de esos lugares es prohibida para personas transexuales o para entrar tienen que pagar 
Los espacios urbanos de sociabilización de los

Transexuales en la ciudad de Santiago de Chile

Mapa $\mathrm{N}^{\mathrm{o}} 1$ : Chile por regiones y Santiago por comunas.

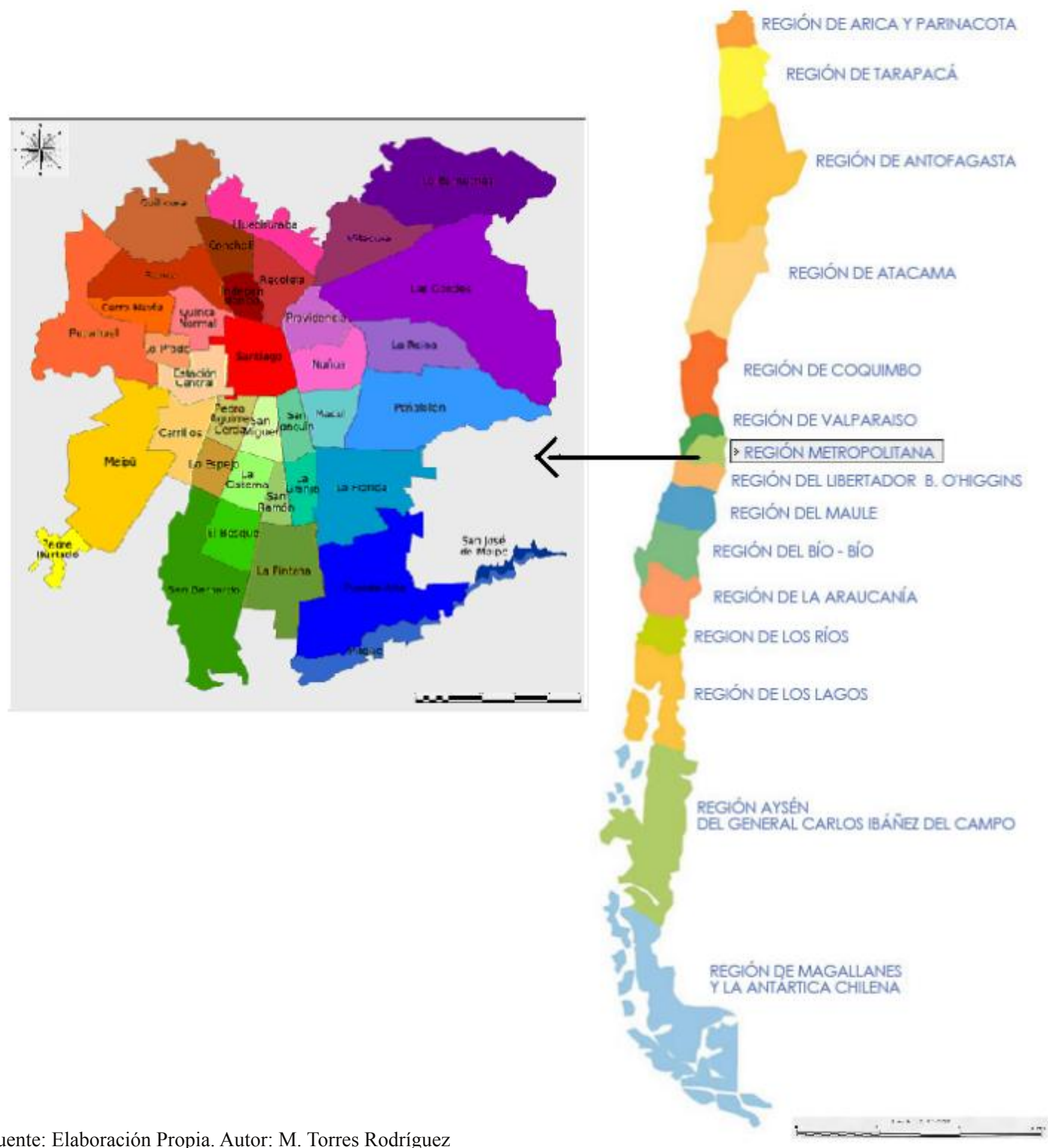

Fuente del dato: Atlas Universal y Chile Regionalizado. José Ignacio

González y Ana María Errázuriz. Editorial: Zig-Zag. 2010. Versión online. 


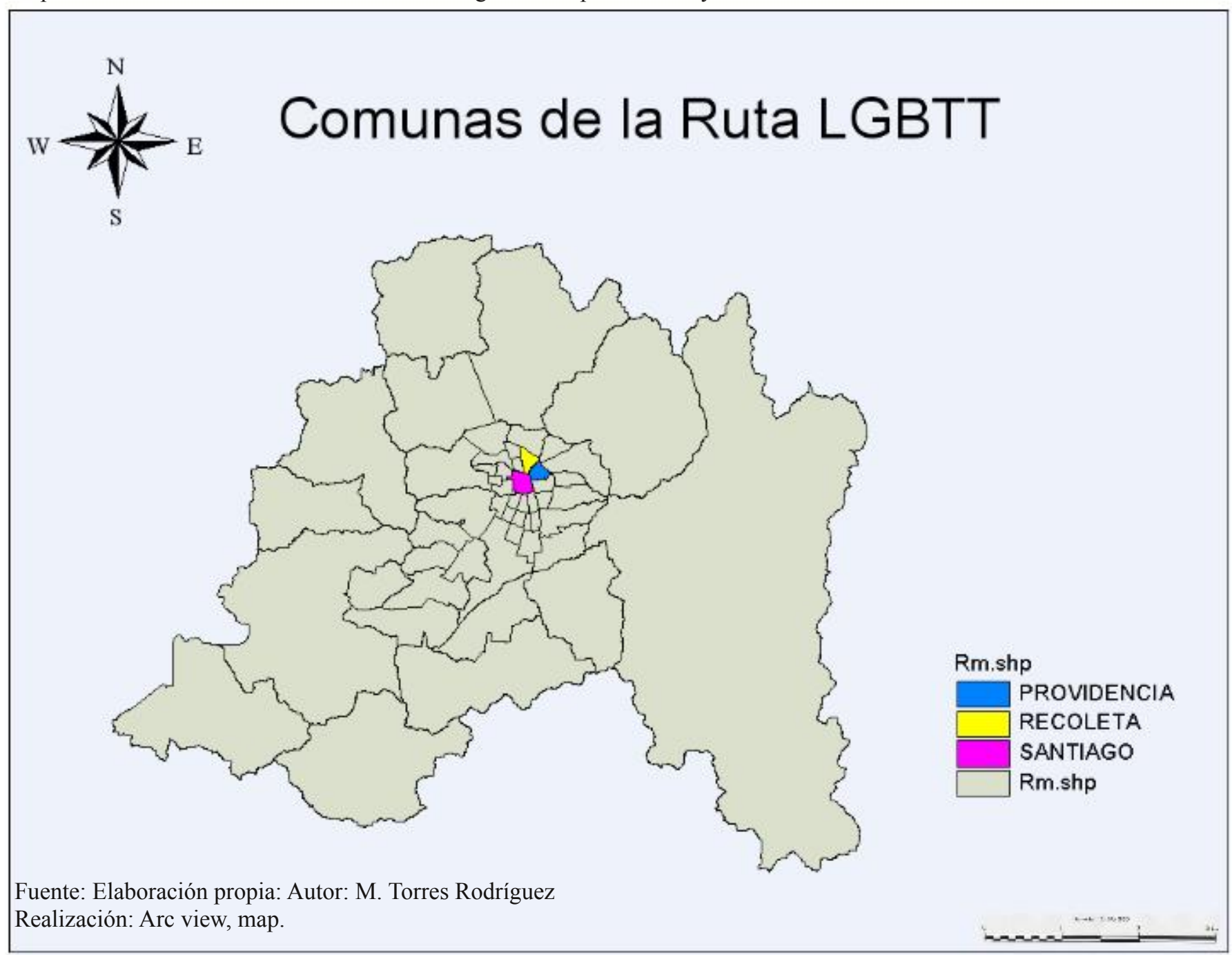

una doble entrada (dada su supuesta condición ambigua).

En este sentido también los transexuales entrevistados coinciden en su mayoría que la ciudad de Santiago (como seguramente también muchas otras capitales, en especial de latino América) no está preparada y no cuenta realmente con espacios de libre expresión para el público transexual, como tampoco cuenta con espacios urbanos de libre tránsito en donde no exista discriminación. En sí, la mayoría de los entrevistados (tanto transexuales hombres como mujeres) coinciden en que Santiago carece de espacios realmente dirigidos para transexuales en donde no se vivencie una discriminación $\mathrm{y}$, en diferentes gamas, coinciden que la discriminación puede ser muy fuerte o moderada.

Es más, no sólo no existen espacios urbanos dirigidos a los transexuales, sino que también la condición transexual es prohibitiva para entrar a otros espacios, sean incluso estos catalogados como LGBTTI, o prohibitivos para entrar a espacios gays o lésbicos, dado que el transexual no es ni una de las dos cosas. También existe una coincidencia en la mayoría de los entrevistados que tampoco la calle o la universidad, como tampoco la escuela, el trabajo e incluso el médico son espacios donde exista libertad, y son justamente en estas instituciones en donde han sentido más fuertemente la discriminación y la transfobia ${ }^{7}$.

$\mathrm{Y}$, de forma unánime, incluso aquellos que consideran que existen espacios de libre expresión transexual y espacios de sociabilización LGBTTI, creen que éstos finalmente no cuentan con una masiva participación de transexuales, ya sea esta falta de 
participación por discriminación o por simple voluntad. En un cien por ciento de los 36 casos entrevistados existe de forma unánime la sensación de que ser libre y expresarse libremente como transexual sólo se vive entre amigos, en organizaciones de

Grafico $N^{o} 1$ : ¿Usted siente que en Santiago existen espacios de libertad de expresión transexual o de la población LGBTTI?
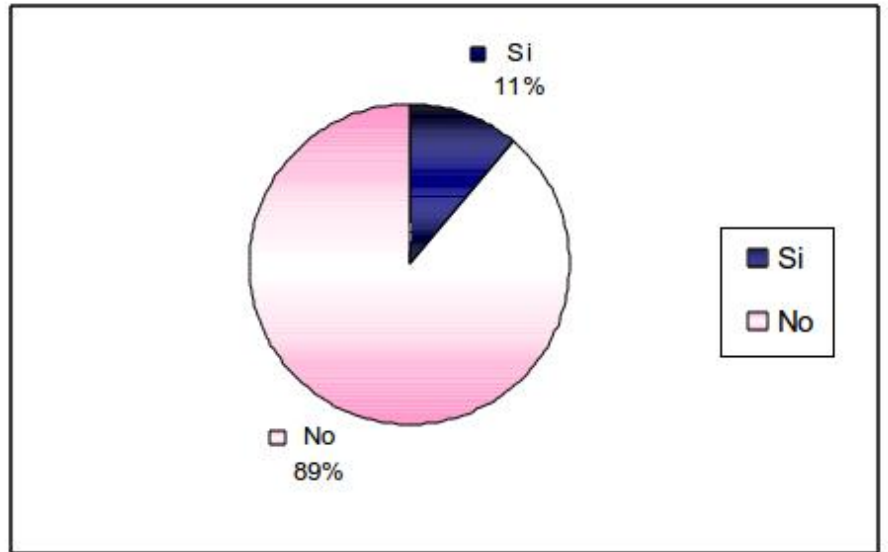

Fuente: Elaboración Propia. Autor: M. Torres Rodríguez transexuales y, con menor frecuencia, en encuentros transexuales, tales como jornadas de trabajo, reuniones, festivales y foros. Ese tipo de situaciones se puede ver claramente en los gráficos $\mathrm{N}^{\mathrm{o}} 1, \mathrm{~N}^{\mathrm{o}} 2, \mathrm{~N}^{\mathrm{o}} 3 \mathrm{y}$ $\mathrm{N}^{0} 4$.
Grafico $N^{\circ} 2: ¿$ Usted siente que en Santiago existen espacios dirigido netamente a la expresión transexual?

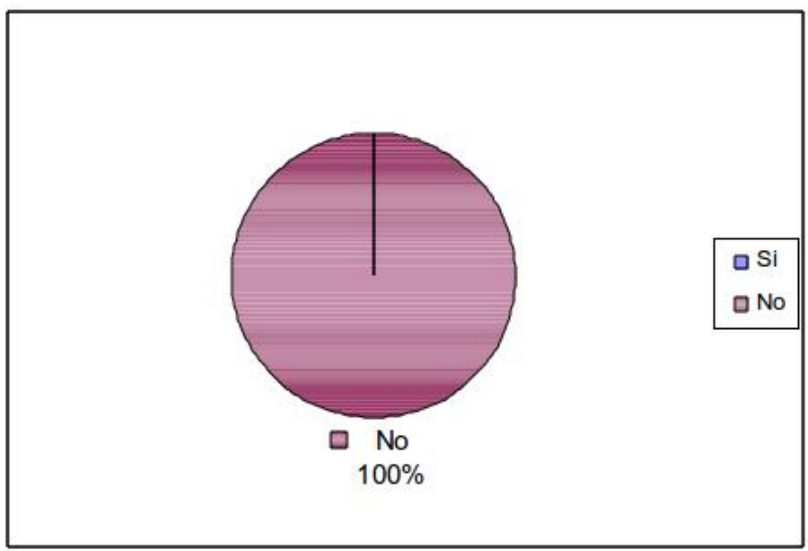

Fuente: Elaboración Propia. Autor: M. Torres Rodríguez

Grafico No 3: ¿Cuáles serian aquellos espacios de sociabilización LGBTTI en Santiago, según usted?

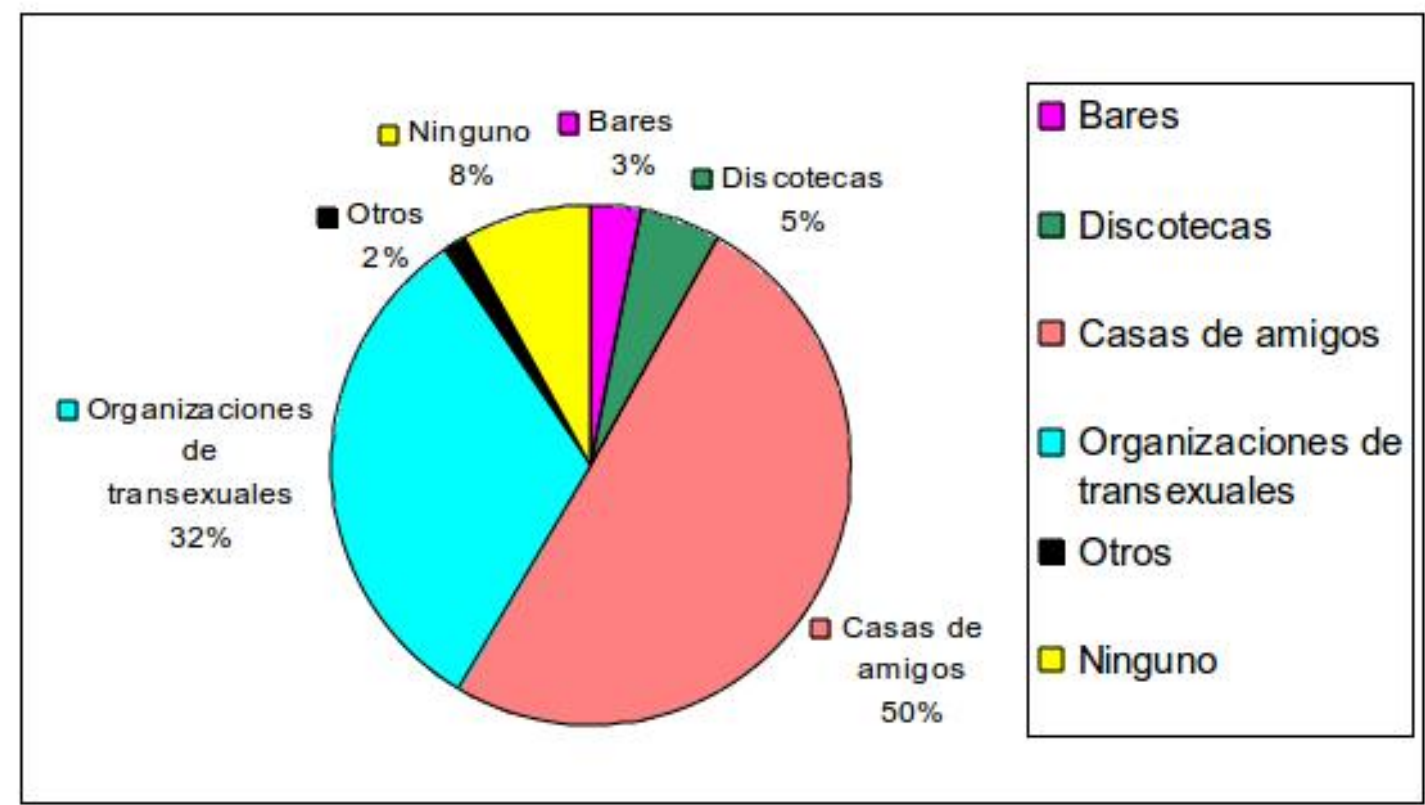

Fuente: Elaboración Propia. Autor: M. Torres Rodríguez 
Grafico No 4: ¿Qué lugares usted suele frecuentar de aquellos mencionados para tener un espacio de sociabilización y esparcimiento?

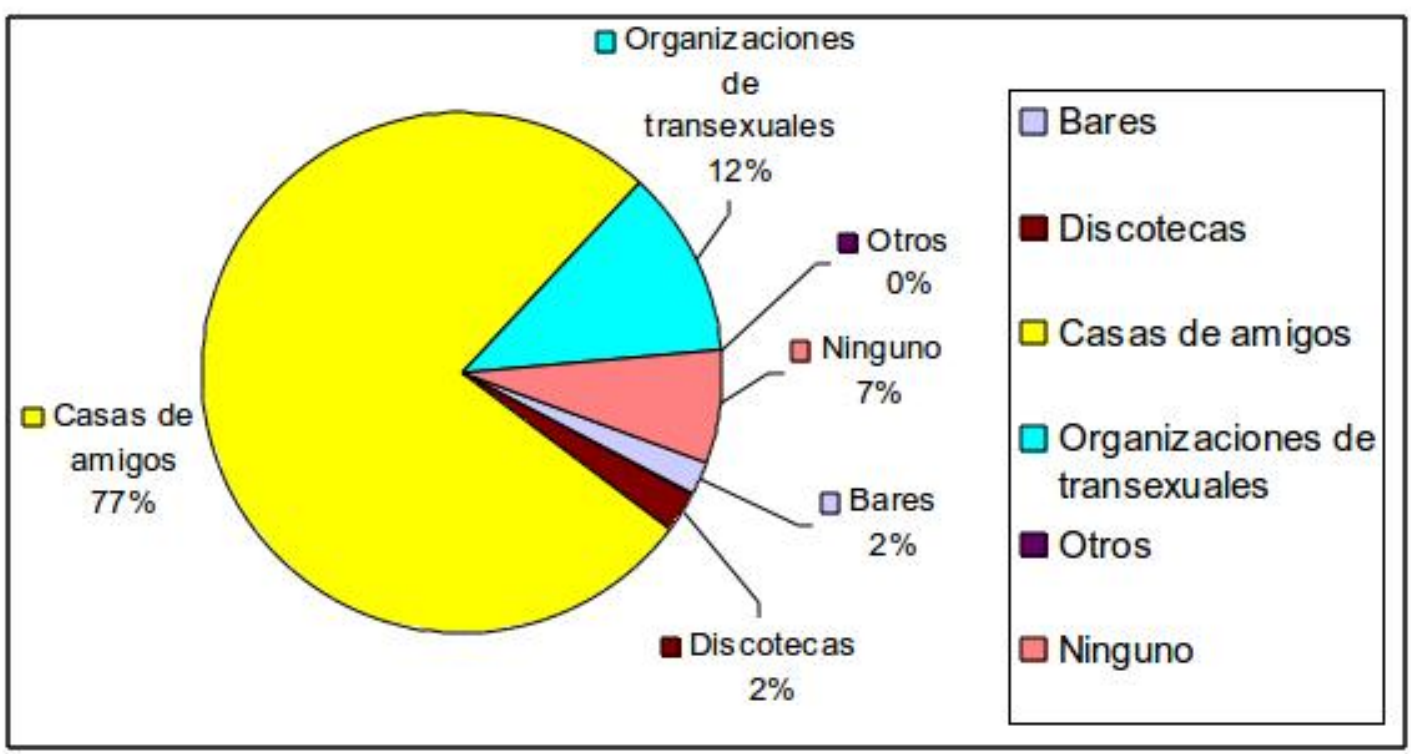

Fuente: Elaboración Propia. Autor: M. Torres Rodríguez

.La ciudad de Santiago cuenta con por lo menos 50 espacios de esparcimiento dirigidos al público LGBTTI (por decir un número por lo bajo) y auto declarados como espacios de libres expresión. Estos lugares se concentran principalmente en el centro de Santiago, salvo con dos excepciones que están en las comunas aledañas del centro de Santiago, las cuales son Recoleta (discoteca Nueva Cero) y Providencia (bar Foxy). En el siguiente mapa se puede apreciar fácilmente la concentración de las tres comunas que monopolizan los espacios LGBTTI en la ciudad de Santiago.

La concentración de los espacios urbanos de sociabilización, catalogados en bares, discotecas y moteles, se presentan en el mapa $\mathrm{N}^{\circ} 3$, representando así los lugares levantados en terreno y los lugares mencionados por los 36 entrevistados, siendo la mayor concentración en el Barrio Bellavista y centro de Santiago.

\section{El Mito y la Invisibilidad}

Se puede observar también, a partir de las entrevistas y las vivencias después del levantamiento de suelo de aquellos lugares mencionados y rotulados como LGBTTI, que existe en estos lugares una connotación más que nada de índole 'gay', en segundo lugar, con un muy bajo perfil, una apertura 'lésbica y bisexual', en un tercer plano está la comunidad 'travesti', y, por debajo de todos ellos, una apertura a recibir e integrar a los transexuales, teniendo en estos espacios una menor visibilidad los transexuales masculinos que las transexuales femeninas. Esto da paso a su vez a dos problemáticas nuevas que surgen en este entorno, tanto del género, del cuerpo, de la psiquis, como del espacio urbano utilizado: El primero es que las transexuales femeninas suelen ser vistas y catalogadas como travestis, generando así la invisibilidad de los transexuales masculinos; y el segundo, es que la sociedad asocia la transexualidad femenina (al igual que el travestismo) con la prostitución y en estos lugares de esparcimiento se genera una situación de mofa, burla y aceptación sólo para generar un show, el cual no siempre es de calidad y es más bien una burla a los seres humanos que somos.

El mayor problema de esta falta de cultura transexual, y en sí de cultura LGBTTI o de cualquier otra minoría, es, como explica Foucault (1976), el sexo, el cual es fundamental para tener una vida sana. En este sentido se genera la problemática del transexual al ingresar en un espacio de supuesta diversidad sexual donde deberían entrar todas aquellas comunidades LGBTTI. Sin embargo, existe una mitificación de los cuerpos transexuales, dejando a éstos a merced de lo gracioso y fuera de las temáticas realmente importantes como lo son el género, la transformación del cuerpo y la territorialización de los espacios, la lucha por apoderarse de espacios urbanos que deberían ser de todos y no sólo de los catalogados 


\section{Lugares LGBT levantados en terreno}
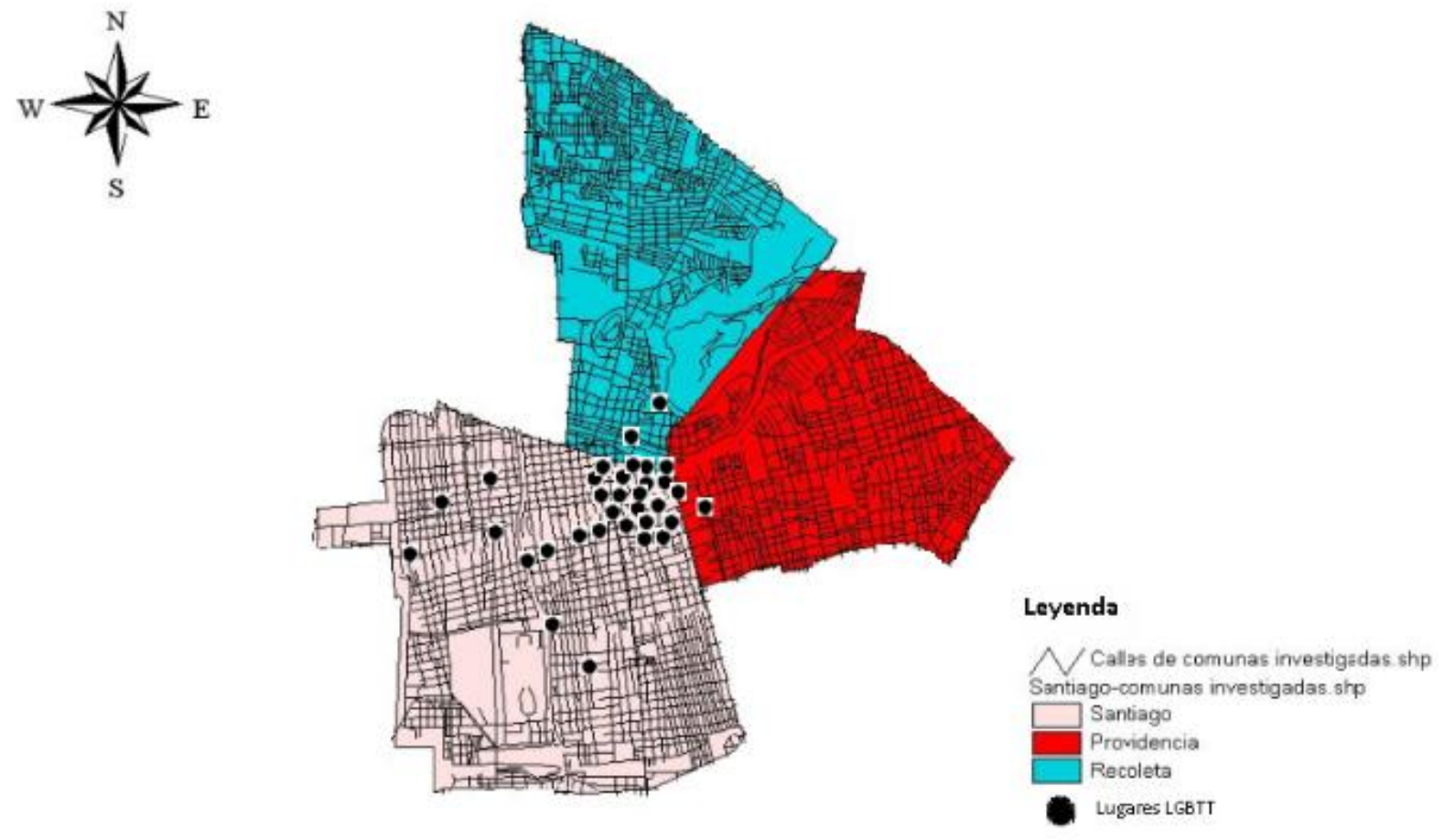

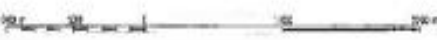

Fuente: Elaboración propia: Autor: M. Torres Rodríguez Realización: Arc view, map.

dentro de la 'buena sociedad', y donde mucho menos debería existir una doble discriminación de parte de aquellos que también han sido discriminados. Es justamente esta situación una de las más dolorosas: la discriminación de las comunidades gays, lésbicas y bisexuales, e incluso, en algunos casos, la discriminación entre los mismos transexuales y las diferencias abismantes que tratan de tener con los travestis. Existe en sí un tema no resuelto entre el cuerpo, la psiquis y el género. Hay un temor dado por la fuerte discriminación y una frustración por el no poder realizar una vida plena dentro de una sociedad que exige ciertos cánones muchas veces incumplibles no sólo por transexuales, sino que por una gran gama de personas que quedan fuera del círculo tan cerrado que es la sociedad y sus normas.

Bajo esta misma perspectiva se encuentra también el querer ser invisible para no generar discriminación, un querer vivir en el anonimato y, por ende, de alguna forma aceptar que la invisibilidad es buena. De los transexuales entrevistados la mayor parte vive en el centro de Santiago, siendo este grupo un $49 \%$ por ciento del universo encuestado, coincidentemente con la concentración de lugares de esparcimiento LGBTTI. Tanto aquellos lugares LGBTTI como también los transexuales que viven en el centro de Santiago tienden a tener un anonimato. Esto se debe ya sea a la cantidad de habitantes del centro de Santiago, como también a la clara individualidad que otorga un centro urbano tan grande y en constante movimiento, lo que da paso a un saberse no identificado y a poder sumergirse en lo invisible del centro capitalino.

De alguna forma las personas que han escogido vivir en el centro de Santiago son, por lo general, 
personas solas y que viven anónimos en su transexualidad, como se puede apreciar en una conversación con una transexual femenina habitante del centro de Santiago, cuando dice:

\begin{abstract}
'(Yo: ¿Sientes que el centro te da anonimato?): V: Sí, sin duda. Vivir en el centro te da como esa libertad....que por ahora para mí es buena, el pasar desapercibida.

...Lo que yo creo, y por qué valoro mi invisibilidad, es porque aún no estoy en el punto en que quiero que todo el mundo se entere. Ahora bien, cuando ya esté lista para salir a la calle como lo que soy, esa misma invisibilidad me servirá para que a todo el mundo le "dé igual".
\end{abstract}

(Yo: ¿Y no seria mejor que la sociedad aceptara a los transexuales como acepta a los rubios, negros, bajos, etc.?): V: Es que no sería lo mismo ser rubio aquí o en África: ahí tu añorarías un poco de invisibilidad (risas). Como tampoco es lo mismo ser negro en el centro de Santiago donde hay tanta gente que da lo mismo, a ser negro en un pueblito de Chile.

...El tema de ser diferente siempre es llamativo. A veces el mundo te puede aceptar pero es mejor pasar desapercibida.

(Yo: ¿La solución para la aceptación de la sociedad será la mayor visibilidad o la educación?): V: La solución a todo es la educación. La sociedad DEBE ser educada para que todos podamos ser libres de ser como queramos ser, sin pasar a llevar a nadie'. ${ }^{8}$

Esta invisibilidad no sólo tiene un doble filo, ya que por una parte ésta puede ser buena, pero finalmente deja el tema del género, una vez más, sumergido en los espacios oscuros de la sociedad. De los 36 entrevistados, 17 viven en el centro de Santiago (12 transexuales masculinos y 6 transexuales femeninas). A pesar de su cercanía con los centros de esparcimiento LGBTTI, éstos no han querido experimentar visitarlos, y/o aquellos que los han visitados se han encontrado con trabas en la entrada, ya sea ésta la negación rotunda de entrar o incluso la condición de tener que pagar mas dinero para poder acceder a los mismo servicios. En sí, los espacios urbanos públicos carecen de una dirección plural en la sociedad y siguen una estructura heteronormativa, en donde la población transexual queda marginalizada inevitablemente.

1 “Así hay un problema lingüístico para ser expuesto en relación a los términos travestí, transgénero y transexual para nominar a personas que poseen una disonancia entre el cuerpo biológico y la identidad de género. La traducción de travestí al ingles seria 'transvestites'. Con todo eso el término en ingles no se adecua a los sujetos aquí enfocados, ya que este término es utilizado para nominar a hombres que se visten 'eventualmente' como mujeres. Las personas aquí enfocadas son mejor definidas, en la lengua inglesa, por la palabra transgender. En español, cualquier persona que realice intervenciones en su cuerpo son nominados de 'transexuales', independiente del grado de intervención, desde el implante de siliconas, hasta la cirugía de reasignación sexual". Traducción libre del autor: M. Torres Rodríguez.

2 "Primero, reconocemos el espacio como el producto de interacciones, siendo construido a través de interacciones, desde la inmensidad de lo global, hasta lo íntimamente pequeño (...) segundo, comprendemos el espacio como la esfera de la posibilidad de la existencia de la multiplicidad, en el sentido de la pluralidad contemporánea, como la esfera en la cual distintas trayectorias coexisten; como la esfera, por tanto, de la coexistencia de la heterogeneidad. Sin espacio, no hay multiplicidad; sin multiplicidad, no hay espacio. Si espacio, es, sin duda, el producto de inter-relaciones, entonces debe estar basado en la existencia de la pluralidad. Multiplicidad es espacio son co-constitutivos. Tercero, reconocemos el espacio como estando siempre en construcción". Traducción libre del autor: M. Torres Rodríguez.

3 Vale entender que el termino Macho, se usa para hombres que nacen con sexo masculino, identidad de genero masculina y son normativamente heterosexuales. Y el término Hembra se denomina para mujeres que nacen con sexo femenino, identidad de género femenina y son normativamente heterosexuales.

4 Sigla para denominar a la población Lésbica, Gay, Bisexual, Travestí, transexual e intersexual.

5 Esta región no se ve afectada con la nueva regionalización de Chile en el año 2007, con la inserción de dos nuevas regiones, la XIV Región de los Ríos y la XV Región de Arica y Parinacota. 
6 Fuente: Atlas Universal y Chile Regionalizado. José Ignacio González y Ana María Errázuriz. Editorial: Zig-Zag. 2010.

7 Es la fobia, o vale decir el miedo inexplicable a los transexuales, la cual puede manifestarse tanto en agresiones verbales como físicas.

8 Se reserva el nombre de la persona entrevistada por motivos de privacidad y protección social.

\section{Referências}

DÍAZ MUÑOZ, Maria de Los Angeles; RODRÍGUEZ MOYA, Juana; SABANTÉ MARTÍNEZ, Ana. Mujeres, espacio y sociedad: Hacia una geografía del género. Madrid: Editorial Síntesis España, 1995.

ESPINOSA PÉREZ, Beatriz. Cuerpos y diversidad sexual: Aportes para la igualdad y el reconocimiento. Bogota: Pontificia Universidad Javeriana Colombia, 2005.

HAMMARBERG, Thomas. Derechos humanos e identidad de género. Estrasburgo: Serie de publicaciones de Trans Respeto versus Transfobia (TvT), v. 1, consejo de Europa - Francia, Enero 2010.

LAQUEUR, Thomas. La construcción del sexo, cuerpo y genero desde los griegos hasta Freud. Madrid: Catédra Edición, 1994.

MASSEY, Doreen. Pelo espaço: Uma nova política de espacialidade. Rio de Janeiro: Bertrad, Brasil, 2005.

SILVA, Joseli Maria. A cidade dos corpos transgressores da heteronormatividade. In: $\mathrm{X}$ Coloquio Internacional de Geocrítica Universidad de Barcelona. 26 - 30 de mayo. 2008. Barcelona. 